\title{
The Danish Intensive Care Database
}

This article was published in the following Dove Press journal:

Clinical Epidemiology

25 October 2016

Number of times this article has been viewed

\section{Christian Fynbo \\ Christiansen' \\ Morten Hylander Møller ${ }^{2}$ \\ Henrik Nielsen' \\ Steffen Christensen ${ }^{3}$ \\ 'Department of Clinical Epidemiology, Institute of Clinical Medicine, Aarhus University Hospital, Aarhus, ${ }^{2}$ Department of Intensive Care 4I3I, Copenhagen University Hospital Rigshospitalet, Copenhagen, ${ }^{3}$ Department of Intensive Care, Aarhus University Hospital, Aarhus, Denmark}

Correspondence: Christian Fynbo Christiansen

Department of Clinical Epidemiology, Aarhus University Hospital, Olof Palmes Alle 43-45, 8200 Aarhus Nord, Denmark Tel +4587168063

Fax +4587167215

Email cfc@clin.au.dk
Aim of database: The aim of this database is to improve the quality of care in Danish intensive care units (ICUs) by monitoring key domains of intensive care and to compare these with predefined standards.

Study population: The Danish Intensive Care Database (DID) was established in 2007 and includes virtually all ICU admissions in Denmark since 2005. The DID obtains data from the Danish National Registry of Patients, with complete follow-up through the Danish Civil Registration System.

Main variables: For each ICU admission, the DID includes data on the date and time of ICU admission, type of admission, organ supportive treatments, date and time of discharge, status at discharge, and mortality up to 90 days after admission. Descriptive variables include age, sex, Charlson comorbidity index score, and, since 2010, the Simplified Acute Physiology Score (SAPS) II. The variables are recorded with $90 \%-100 \%$ completeness in the recent years, except for SAPS II score, which is $73 \%-76 \%$ complete. The DID currently includes five quality indicators. Process indicators include out-of-hour discharge and transfer to other ICUs for capacity reasons. Outcome indicators include ICU readmission within 48 hours and standardized mortality ratios for death within 30 days after admission using case-mix adjustment (initially using age, sex, and comorbidity level, and, since 2013, using SAPS II) for all patients and for patients with septic shock.

Descriptive data: The DID currently includes 335,564 ICU admissions during 2005-2015 (average 31,958 ICU admissions per year).

Conclusion: The DID provides a valuable data source for quality monitoring and improvement, as well as for research.

Keywords: critical care, databases, health care quality, intensive care

\section{Background}

Danish intensive care units (ICUs) provide publicly funded intensive care to all Danish inhabitants. Intensive care includes observation, diagnostics, treatment, and care for patients with potentially reversible failure of one or more organ systems. Three different levels of intensive care exist: levels 1, 2, and 3 according to the level of staffing, equipment, and available medical specialties. ${ }^{1}$ In Denmark, $2.2 \%$ of all acute care hospital beds are in ICUs, which is lower than in most other European countries. ${ }^{2}$ Danish ICUs are operated by anesthesiologists and/or intensivists, and any transfer to the ICU is at the discretion of the ICU physician on call. Admission to ICU depends, among others, on the severity of illness and the expected benefit, including reversibility of the condition. 
The Danish Intensive Care Database (DID) was established in 2007 preceded by a 2-year collaboration between a working group of the Danish Society for Anesthesiology and Intensive Care, the Danish Society for Intensive Care, and the Department of Clinical Epidemiology, Aarhus University Hospital. ${ }^{3}$

To reduce registration workload for the clinical departments, the database was established using data already routinely reported by the ICUs to the Danish National Registry of Patients (DNRP). ${ }^{3,4}$ The DNRP contains data on all non-psychiatric hospital admissions in Denmark since 1977 and on outpatient clinic and emergency room visits since $1995 .^{5}$ Reporting to the DNRP is mandatory for all Danish hospitals. Data in the registry include dates of hospital admission and discharge, diagnoses, and procedures. The DNRP has increasingly been used for productivity monitoring and financial reimbursement of Danish hospitals, including intensive care from 2004. Since 2005, the DNRP comprises virtually complete data on ICU admission, mechanical ventilation, inotropes/vasopressors, and renal replacement therapy. However, additional relevant variables regarding ICU stay were subsequently included and implemented in the DNRP on request from the DID. ${ }^{3-5}$

\section{Aim of the database}

The aim of the DID is to improve the quality of care in the Danish ICUs by monitoring key domains of intensive care and to compare these with predefined standards.

\section{Study population}

The DID includes 335,564 admissions to an ICU in Denmark from January 1, 2005, when reporting to the DNRP became mandatory through June 30, 2015. On average, 31,958 admissions are included each year. ICU admissions are identified by procedure codes for intensive care therapy or observation (Danish procedure codes: NABB and NABE), which are used interchangeably.

A frequently updated list of ICU department codes is used to exclude $5 \%-7 \%$ of registered procedure codes for intensive care that are recorded by non-ICU departments, eg, coronary care units and pediatric departments.

Only Danish citizens are included in the DID, because follow-up of death using the Danish Civil Registration System (DCRS) is not available for visitors. ${ }^{6}$

\section{Main variables}

The DID includes variables regarding patient characteristics, baseline characteristics, organ supportive treatment, ICU admission and discharge, quality indicators, and outcome (Table 1).

\section{Patient characteristics}

The Charlson comorbidity index score is computed using data from the DNRP on all primary and secondary diagnoses from all Danish hospital admissions since 1977, and, since 1995, from outpatient clinic and emergency room visits as well. ${ }^{7}$

Severity of illness at ICU admission is registered using the Simplified Acute Physiology Score (SAPS) II, which was originally developed in a European-American setting of adult ICU patients ( $\geq 18$ years), excluding patients with burn and myocardial ischemia and patients undergoing cardiac surgery. ${ }^{8}$ The SAPS II has been registered in the DID from 2010 and is registered for patients aged 16 years or older admitted for $>24$ hours (Table 2). DID holds data on the cumulative score of each patient but not on variables included in estimation of the score.

\section{ICU admission, treatments, and discharge}

The day and time of ICU admission is recorded for all ICU admissions. ICU admission type is divided into elective surgical, emergency surgical, and medical, corresponding to the definition in the SAPS II. ${ }^{8}$

The DID includes procedure code data on organ supportive treatment, including invasive and noninvasive mechanical

Table I Variables in the Danish Intensive Care Database

\section{Patient characteristics}

Personal identification number

Age

Sex

Charlson comorbidity index score (using hospital contacts since 1977)

ICU admission

ICU admission date and time

ICU department code

ICU name

Patient category (elective surgical, emergency surgical, or nonsurgical) SAPS II

Mechanical ventilation (yes/no)

Duration of mechanical ventilation

Noninvasive ventilation (yes/no)

Renal replacement therapy (yes/no)

Use of inotropes or vasopressors (yes/no)

Date and time of any septic shock diagnosis

ICU discharge

Discharge status (transfer to ward, transfer to other ICUs for capacity reasons, transfer to other ICU on clinical indication, or death in ICU)

Date and time of ICU discharge

Mortality

ICU mortality

Death within 2 days after ICU discharge

In-hospital mortality

30-day mortality

30-day mortality following septic shock

90-day mortality

Abbreviations: ICU, intensive care unit; SAPS, Simplified Acute Physiology Score. 
Table 2 Completeness (\%) of core variables included in the Danish Intensive Care Database

\begin{tabular}{|c|c|c|c|c|c|c|c|c|c|c|c|}
\hline & 2005 & 2006 & 2007 & 2008 & 2009 & 2010 & 2011 & 2012 & 2013 & 2014 & $\begin{array}{l}2015 \\
Q 1+Q 2\end{array}$ \\
\hline Number of admissions & 30,692 & 32,496 & 32,513 & 30,947 & 31,877 & 32,825 & 32,309 & 32,197 & 32,483 & 31,574 & $|5,65|$ \\
\hline \multicolumn{12}{|l|}{ Patient characteristics } \\
\hline Personal identification number & 100 & 100 & 100 & 100 & 100 & 100 & 100 & 100 & 100 & 100 & 100 \\
\hline Age & 100 & 100 & 100 & 100 & 100 & 100 & 100 & 100 & 100 & 100 & 100 \\
\hline Sex & 100 & 100 & 100 & 100 & 100 & 100 & 100 & 100 & 100 & 100 & 100 \\
\hline Charlson comorbidity index score & 100 & 100 & 100 & 100 & 100 & 100 & 100 & 100 & 100 & 100 & 100 \\
\hline \multicolumn{12}{|l|}{ ICU admission } \\
\hline ICU admission date and time & 100 & 100 & 100 & 100 & 100 & 100 & 100 & 100 & 100 & 100 & 100 \\
\hline ICU department code & 100 & 100 & 100 & 100 & 100 & 100 & 100 & 100 & 100 & 100 & 100 \\
\hline ICU name & 100 & 100 & 100 & 100 & 100 & 100 & 100 & 100 & 100 & 100 & 100 \\
\hline $\begin{array}{l}\text { Patient category (elective surgical, } \\
\text { emergency surgical, or nonsurgical) }\end{array}$ & - & - & - & 1.2 & 58.5 & 74.9 & 78.6 & 84.8 & 86.4 & 89.9 & 94.8 \\
\hline SAPS $\|^{\mathrm{a}}$ & - & - & - & 0.0 & 0.0 & 23.8 & 60.6 & 73.1 & 76.2 & 73.5 & 73.7 \\
\hline Mechanical ventilation & b & b & b & b & b & b & b & $\mathrm{b}$ & b & b & b \\
\hline Duration of mechanical ventilation & - & - & - & 0.0 & 0.0 & 0.6 & 64.0 & 77.2 & 92.1 & 93.8 & 95.2 \\
\hline Noninvasive ventilation & b & b & $\mathrm{b}$ & b & b & b & $\mathrm{b}$ & b & b & $\mathrm{b}$ & b \\
\hline Renal replacement therapy & $\mathrm{b}$ & $\mathrm{b}$ & b & $\mathrm{b}$ & $\mathrm{b}$ & $\mathrm{b}$ & b & b & $\mathrm{b}$ & $\mathrm{b}$ & $\mathrm{b}$ \\
\hline Use of inotropes or vasopressors & b & b & b & $\mathrm{b}$ & b & b & $\mathrm{b}$ & b & $\mathrm{b}$ & b & b \\
\hline $\begin{array}{l}\text { Date and time of any septic shock } \\
\text { diagnosis }\end{array}$ & b & $\mathrm{b}$ & b & $\mathrm{b}$ & b & b & b & b & b & $\mathrm{b}$ & $\mathrm{b}$ \\
\hline \multicolumn{12}{|l|}{ ICU discharge } \\
\hline Discharge status $^{c}$ & - & - & - & 1.6 & 59.3 & 77.5 & 79.2 & 84.1 & 85.7 & 88.9 & 95.6 \\
\hline Date and time of ICU discharge & - & - & - & 0.7 & 46.6 & 72.4 & 78.7 & 83.8 & 87.0 & 89.7 & 95.1 \\
\hline \multicolumn{12}{|l|}{ Mortality } \\
\hline ICU mortality & - & - & - & 1.6 & 59.3 & 77.5 & 79.2 & 84.1 & 85.7 & 88.9 & 95.6 \\
\hline $\begin{array}{l}\text { Death within } 2 \text { days after ICU } \\
\text { discharge }\end{array}$ & - & - & - & 0.7 & 46.6 & 72.4 & 78.7 & 83.8 & 87.0 & 89.7 & 95.1 \\
\hline In-hospital mortality & 100 & 100 & 100 & 100 & 100 & 100 & 100 & 100 & 100 & 100 & 100 \\
\hline 30-day mortality & 100 & 100 & 100 & 100 & 100 & 100 & 100 & 100 & 100 & 100 & 100 \\
\hline 90-day mortality & 100 & 100 & 100 & 100 & 100 & 100 & 100 & 100 & 100 & 100 & 100 \\
\hline
\end{tabular}

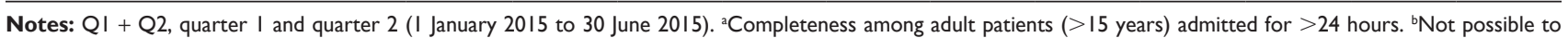
estimate completeness without external data source, because only the presence of treatment is coded. Including transfer to ward, transfer to other ICU for capacity reasons, transfer to other ICU on clinical indication, and death in ICU.

Abbreviations: ICU, intensive care unit; SAPS, Simplified Acute Physiology Score.

ventilation, use of inotropes/vasopressors, and renal replacement therapy. Duration of invasive mechanical ventilation is optionally registered since 2011.

Data on discharge status includes transfer to ward, transfer to other ICU due to lack of capacity, transfer to other ICU on clinical indication, and death in ICU. Data and time of ICU discharge are also registered since 2009.

\section{Mortality}

ICU mortality is reported by the ICUs upon discharge from the ICU. Complete follow-up for any later death or emigration is obtained from the DCRS. Mortality measures include ICU death, death on the day of or the day after ICU discharge, hospital death (death registered in the DCRS on or before the day of last discharge from the entire hospital stay), death within 30 days, and death within 90 days after ICU admission. ${ }^{6}$

\section{Quality indicators}

The DID currently includes five quality indicators, including two process indicators and three outcome indicators. Each indicator has a quality standard cut point that is reconsidered annually in order to secure clinically meaningful improvement. Two of the included indicators have reached $>90 \%$ consensus in the Delphi process conducted by the task force for the identification of quality indicators of intensive care established by the European Society of Intensive Care Medicine (Table 2). ${ }^{9}$

The two process indicators include discharge to ward between $10 \mathrm{pm}$ and 8 am (out-of-hours) and transfer to other ICUs due to the lack of ICU capacity.

The three outcome indicators are ICU readmission within 48 hours after discharge to the ward, standardized mortality ratio (SMR) in all patients, and separate for patients with septic shock (Table 3). SMR is computed for death within 30 days after ICU admission. 
SMR is computed by indirect standardization as the ratio between the observed number of deaths and the expected number of deaths for the case-mix of each ICU. Case-mix was defined by age, sex, and Charlson comorbidity index score from 2007 to 2012 and by SAPS II thereafter. ${ }^{8}$ In the latter analysis, only patients with a registered SAPS II are included, ie, patients older than 15 years and admitted for $\geq 24$ hours.

The rate of ventilator-associated pneumonia per ventilatordays was included as an indicator in the DID in 2011 and 2012 but discontinued because of incomplete registration.

Previously, three indicators were obtained annually at the ICU level by an electronic questionnaire including the following: standardized handover procedure for discharging patients, whether the ICU fulfilled the National Board of Health's requirements to the level of ICU, and whether an anesthesiologist/consultant-level intensivist was available in the hospital 24/7. These three indicators were discontinued because most of the ICUs fulfilled the indicators, which limited further improvement.

\section{Data quality and missing data}

The DID includes data from virtually all ICU admissions in Denmark (43 ICUs as of January 1, 2015). The included number of admissions is considered to be $\sim 95 \%$ complete, based on the reporting of minor discrepancy compared with local registrations at individual ICUs, as described in the annual report. ${ }^{10}$ Not all relevant data are automatically transferred to the DID through the hospitals' electronic health records or patient administrative systems to the DNRP; but they rather rely on re-entry by a medical secretary of the department responsible for the patients.

The accuracy of the registered ICU admissions is, in general, high. Despite the fact that the DNRP does not exclude patients coded with intensive care provided by nonICUs, the proportion of ICU admissions registered in the DNRP confirmed by medical record review is $96 \%-99 \%$ for ICU patients overall (positive predictive value [PPV]). ${ }^{11,12}$ The PPV is somewhat lower (87\%) when restricting to registrations of intensive care without concurrent coding for mechanical ventilation or dialysis because some hospital codes record a stay in the postoperative recovery room as an ICU admission. Mechanical ventilation and dialysis are coded with a PPV of $100 \%$ and $98 \%$, respectively. ${ }^{12}$ The other variables added by the DID in 2008/2009, including reason for admission, time of discharge, and status at discharge, have been validated only internally. However, most had a completeness of $45 \%-60 \%$ in the first years, increasing to $90 \%-95 \%$ in the recent years (Table 3). While most ICUs have completeness close to $100 \%$, neurosurgical ICUs just recently started reporting data, with a resulting lower completeness. This also contributes to the completeness of SAPS II, which is still $74 \%$ for adult patients (15 years or older) admitted to the ICU for $>24$ hours.

In order to secure and improve data quality, the DID offers local validation of data by comparing data from local system extractions with data in the DID.

\section{Follow-up}

Patients included in the DID are followed from the day of ICU admission and until death or loss to follow-up, eg, at time of emigration or at the cut-off date for the data extraction from the DCRS for the recent annual report.

\section{Examples of research}

Data from the DID are currently being used for several research projects addressing the variation of intensive care utilization and prognosis of intensive care. While several Danish studies have used similar data from the DNRP to examine the impact of comorbidity and preadmission drug use on the prognosis of intensive care, ${ }^{13-18}$ only few published studies are so far based on the data from the DID. One study found more use of intensive care in patients undergoing elective surgery for aortic aneurysm than for aortic occlusive disease. ${ }^{19}$ Another study found geographical variation in use of intensive care, in particular between the municipalities. ${ }^{20}$ The number of studies using DID is expected to increase with the increasing validity of the DID and the improved infrastructure and data access of the Danish Clinical Registries.

\section{Administrative issues and funding}

The DID is funded by the Danish Regions, and receives administrative, epidemiological, and biostatical support from the Danish Clinical Registries, Danish Regions. The steering committee includes clinicians from each of the Danish regions, from the Danish Society of Anesthesiology and Intensive Care Medicine as well as from a representative for the region responsible for the database (Central Denmark Region), and a clinical epidemiologist. Aggregated data at ICU level are reported annually in a published report, and individual-level data are provided monthly to relevant clinicians and hospital managers through each region's information system. A structured clinical audit process is included 
Table 3 Quality indicators in the Danish Intensive Care Database 2005-20I5

\begin{tabular}{|c|c|c|c|c|c|c|c|c|c|c|c|c|}
\hline $\begin{array}{l}\text { Individual level } \\
\text { indicators }\end{array}$ & Definition & Domain & 2006 & 2007 & 2008 & 2009 & 2010 & 2011 & 2012 & 2013 & 2014 & 2015 \\
\hline $\begin{array}{l}\text { ICU readmission } \\
\text { within } 48 \text { hours }\end{array}$ & $\begin{array}{l}\text { Proportion of patients readmitted } \\
\text { to an ICU within } 48 \text { hours of } \\
\text { discharge }\end{array}$ & Outcome & - & - & - & $\checkmark$ & $\checkmark$ & $\checkmark$ & $\checkmark$ & $\checkmark$ & $\checkmark$ & $\checkmark$ \\
\hline Nighttime discharge & $\begin{array}{l}\text { Proportion of patients discharged } \\
\text { to the ward between } 10 \mathrm{pm} \text { and } \\
8 \text { am (out-of-hours) }\end{array}$ & Process & - & - & - & $\checkmark$ & $\checkmark$ & $\checkmark$ & $\checkmark$ & $\checkmark$ & $\checkmark$ & $\checkmark$ \\
\hline $\begin{array}{l}\text { Capacity transfer to } \\
\text { other ICU }\end{array}$ & $\begin{array}{l}\text { Proportion of patients } \\
\text { transferred to another ICU for } \\
\text { capacity reasons }\end{array}$ & Process & - & - & - & - & $\checkmark$ & $\checkmark$ & $\checkmark$ & $\checkmark$ & $\checkmark$ & $\checkmark$ \\
\hline $\begin{array}{l}\text { Ventilator-associated } \\
\text { pneumonia }\end{array}$ & $\begin{array}{l}\text { Number of patients with } \\
\text { ventilator-associated pneumonia } \\
\text { per ventilator-days for patients } \\
\text { intubated and ventilated for } \\
\geq 48 \text { hours }\end{array}$ & Outcome & - & - & - & - & - & $\checkmark$ & $\checkmark$ & - & - & - \\
\hline SMR & $\begin{array}{l}\text { Number of observed deaths } \\
\text { within } 30 \text { days divided by the } \\
\text { expected number of deaths } \\
\text { based on case-mix }\end{array}$ & Outcome & - & $\checkmark$ & $\checkmark$ & $\checkmark$ & $\checkmark$ & $\checkmark$ & $\checkmark$ & $\checkmark$ & $\checkmark$ & $\checkmark$ \\
\hline SMR in septic shock & $\begin{array}{l}\text { Number of observed deaths } \\
\text { within } 30 \text { days after septic shock } \\
\text { or ICU admission divided by the } \\
\text { expected number of deaths based } \\
\text { on case-mix }\end{array}$ & Outcome & - & - & - & - & - & - & - & $\checkmark$ & $\checkmark$ & $\checkmark$ \\
\hline \multicolumn{13}{|l|}{ ICU level indicators } \\
\hline $\begin{array}{l}\text { ICU fulfills national } \\
\text { requirements }\end{array}$ & $\begin{array}{l}\text { Fulfillment of the National Board } \\
\text { of Health's requirement for the } \\
\text { level of the ICU }\end{array}$ & Structure & - & - & - & - & - & $\checkmark$ & $\checkmark$ & $\checkmark$ & - & - \\
\hline $\begin{array}{l}\text { Availability of } \\
\text { anesthesiology } \\
\text { specialist } 24 / 7\end{array}$ & $\begin{array}{l}\text { Immediate in-hospital availability } \\
\text { of an intensive care or } \\
\text { anesthesiology specialist } 24 \text { hours } \\
\text { per day, } 7 \text { days a week }\end{array}$ & Structure & - & - & - & - & - & $\checkmark$ & $\checkmark$ & $\checkmark$ & - & - \\
\hline $\begin{array}{l}\text { Standardized handover } \\
\text { procedure for } \\
\text { discharging patients }\end{array}$ & $\begin{array}{l}\text { A structured handover } \\
\text { procedure is used for all } \\
\text { discharges }\end{array}$ & Process & - & - & - & - & - & $\checkmark$ & $\checkmark$ & $\checkmark$ & - & - \\
\hline
\end{tabular}

Notes: aCase-mix was defined by age, sex, and comorbidity level until 2013 and by SAPS II thereafter; -, Not included this year; $\checkmark$, included this year.

Abbreviations: ICU, intensive care unit; SAPS, Simplified Acute Physiology Score; SMR, standardized mortality ratio.

in the annual steering committee meeting in order to assess the results and add explanations and clinical interpretations to guide future monitoring and improvement. At this annual audit, it is also considered whether there is a need to change the quality indicators or the quality standard cut points, eg, it has now been decided to decrease the standard cut point for several quality indicators including readmission, nighttime discharge, and capacity transfer because most ICUs now fulfill the standards that give opportunity for further improvement. Comments and conclusions from the audit are published in the annual report.

Data extraction for quality purposes and research is possible according to current guidelines, and the procedure for application is available on the website of the Danish Clinical Registries (RKKP). ${ }^{21}$

\section{Conclusion}

The DID includes all patients admitted to the ICU in Denmark and is a valuable data source for quality monitoring and improvement, as well as for research.

\section{Acknowledgments}

This article was funded by the Program for Clinical Research Infrastructure established by the Lundbeck Foundation and the Novo Nordisk Foundation and administered by the Danish Regions. This study was conducted on behalf of the Danish Intensive Care Database.

\section{Disclosure}

$\mathrm{CFC}$ and $\mathrm{HN}$ are the employees of Department of Clinical Epidemiology, Aarhus University Hospital, which receives 
funding from the Danish Clinical Registries (RKKP), Danish Regions, for managing the Danish Intensive Care Database. The authors report no other conflicts of interest in this work.

\section{References}

1. Sundhedsstyrelsen [webpage on the Internet]. Intensiv terapi definitioner, dokumentation og visitationsprincipper [Intensive care therapy - definitions, documentation and visitation principle]; 2006. Available from: https://sundhedsstyrelsen.dk/da/udgivelser/2006/ / media/56E42E9270CD4CCF8AF1941617AFB7E1.ashx. Accessed February 11, 2016.

2. Rhodes A, Ferdinande P, Flaatten H, Guidet B, Metnitz PG, Moreno RP. The variability of critical care bed numbers in Europe. Intensive Care Med. 2012;38:1647-1653.

3. Ronholm E, Christensen S, Andersen JS, Jensen RH, Sorensen HT. Kliniske databaser for kritisk syge patienter [Clinical database for intensive care patients]. Ugeskr Laeger. 2007;169:724-727. Danish.

4. Christiansen CF, Ronholm E. Dansk Intensiv Database [Danish intensive care database]. Ugeskr Laeger. 2012;174:2544. Danish.

5. Schmidt M, Schmidt SA, Sandegaard JL, Ehrenstein V, Pedersen L, Sorensen HT. The Danish National Patient Registry: a review of content, data quality, and research potential. Clin Epidemiol. 2015;7:449-490.

6. Schmidt M, Pedersen L, Sorensen HT. The Danish Civil Registration System as a tool in epidemiology. Eur J Epidemiol. 2014;29:541-549.

7. Thygesen SK, Christiansen CF, Christensen S, Lash TL, Sorensen HT. The predictive value of ICD-10 diagnostic coding used to assess Charlson comorbidity index conditions in the population-based Danish National Registry of Patients. BMC Med Res Methodol. 2011;11:83.

8. Le Gall JR, Lemeshow S, Saulnier F. A new Simplified Acute Physiology Score (SAPS II) based on a European/North American multicenter study. JAMA. 1993;270:2957-2963.

9. Rhodes A, Moreno RP, Azoulay E, et al; Task Force on Safety and Quality of European Society of Intensive Care Medicine (ESICM). Prospectively defined indicators to improve the safety and quality of care for critically ill patients: a report from the Task Force on Safety and Quality of the European Society of Intensive Care Medicine (ESICM). Intensive Care Med. 2012;38:598-605.

10. Sundhed.dk [webpage on the internet]. Copenhagen. Available from: https://www.sundhed.dk/sundhedsfaglig/kvalitet/kliniske-kvalitetsdatabaser/specifikke-procedurer/intensiv-database/. Accessed March 10, 2016.
11. Christiansen CF, Christensen S, Johansen MB, Larsen KM, Tonnesen E, Sorensen HT. The impact of pre-admission morbidity level on 3-year mortality after intensive care: a Danish cohort study. Acta Anaesthesiol Scand. 2011;55:962-970.

12. Blichert-Hansen L, Nielsson MS, Nielsen RB, Christiansen CF, Norgaard M. Validity of the coding for intensive care admission, mechanical ventilation, and acute dialysis in the Danish National Patient Registry: a short report. Clin Epidemiol. 2013;5:9-12.

13. Christensen S, Thomsen RW, Johansen MB, et al. Preadmission statin use and one-year mortality among patients in intensive care - a cohort study. Crit Care. 2010;14:R29.

14. Christensen S, Johansen MB, Tonnesen E, et al. Preadmission betablocker use and 30-day mortality among patients in intensive care: a cohort study. Crit Care. 2011;15:R87.

15. Christensen S, Johansen MB, Pedersen L, et al. Three-year mortality among alcoholic patients after intensive care: a population-based cohort study. Crit Care. 2012;16:R5.

16. Christiansen CF, Johansen MB, Christensen S, O'Brien JM, Tonnesen E, Sorensen HT. Type 2 diabetes and 1-year mortality in intensive care unit patients. Eur J Clin Invest. 2013;43:238-247.

17. Christiansen CF, Johansen MB, Christensen S, O’Brien JM, Tonnesen E, Sorensen HT. Preadmission metformin use and mortality among intensive care patients with diabetes: a cohort study. Crit Care. 2013;17:R192.

18. Wunsch H, Christiansen CF, Johansen MB, et al. Psychiatric diagnoses and psychoactive medication use among nonsurgical critically ill patients receiving mechanical ventilation. JAMA. 2014;311:1133-1142.

19. Bisgaard J, Gilsaa T, Ronholm E, Toft P. Aortic aneurysm disease vs aortic occlusive disease: differences in outcome and intensive care resource utilisation after elective surgery: an observational study. Eur J Anaesthesiol. 2013;30:65-72.

20. Vestergaard AH, Christiansen CF, Nielsen H, Christensen S, Johnsen SP. Geographical variation in use of intensive care: a nationwide study. Intensive Care Med. 2015;41:1895-1902.

21. www.rkkp.dk [webpage on the internet]. Aarhus: Regionernes Kliniske Kvalitetsudviklingsprogram. [the Danish Clinical Registries]. Accessed March 10, 2016.
Clinical Epidemiology

\section{Publish your work in this journal}

Clinical Epidemiology is an international, peer-reviewed, open access, online journal focusing on disease and drug epidemiology, identification of risk factors and screening procedures to develop optimal preventative initiatives and programs. Specific topics include: diagnosis, prognosis, treatment, screening, prevention, risk factor modification,

Submit your manuscript here: http://www.dovepress.com/clinical-epidemiology-journal

\section{Dovepress}

systematic reviews, risk \& safety of medical interventions, epidemiology \& biostatistical methods, and evaluation of guidelines, translational medicine, health policies \& economic evaluations. The manuscript management system is completely online and includes a very quick and fair peer-review system, which is all easy to use. 